\title{
Locating Facts Devices in Optimized manner in Power System by Means of Sensitivity Analysis
}

\author{
K.K.Gautam, \\ Assistant professor Department of Electrical \\ Engineering Rustamji Institute of Technology B.S.F. \\ Academy Tekanpur
}

\author{
Arun.K.S. Tomar \\ Assistant professor Department of Electrical \\ Engineering Rustamji Institute of Technology B.S.F. \\ Academy Tekanpur
}

\begin{abstract}
This paper presents a new method to find the optimal location of facts devices by analyzing sensitivity . The optimal location and capability of Static Var Compensator (SVC) and Thyristor Controlled Series Capacitor (TCSC) in transmission line is investigated for enchasing the power transfer capability and stability of the system. The method firstly put all the buses in the order by voltage reactive power sensitivity and then chooses the optimal location and appropriate capability of the facts devices. It is simple in computation and suitable for large scale interconnection power grid. The results obtained are satisfying and will be useful for enhancing the power system reliability.

Index Terms: Capability, compensation, FACTS devices, optimal location, reactive power, sensitivity analysis, STATCOM, SVC, TCSC.
\end{abstract}

\section{I INTRODUCTION}

The practices and concepts in modern power system are experiencing rapid change along with and due to deregulation of Electricity markets and underlining impact of Distributed Generation. Overloading of transmission lines due to Bilateral Power purchase agreements and efforts to transmit cheap power from generator bus to load bus tend to destabilize the existing system .In order to increase the loadability, reduce system losses and improve system stability , and reduction in power production cost calls for search of new fast and better control and compensation strategies. Flexible ac transmission system (FACTS) such as Static Var Compensator (SVC), Thyristor controlled series compensation (TCSC) etchave proved to be parts of effective control and compensation strategies [1] [2] [3] [4], However there main function is to control the power by controlling the parameters such as transmission line impedances, terminal voltages and voltage angle. In this work a methodology to choose optimal location of SVC and TCSC using sensitivity analysis is proposed .The proposed method put all the busses of the system in order by voltage reactive power sensitivity before choosing the optimal location of compensators. The proposed method considers static voltage and transient stability. It is simple in compensation and suitable for large scale integrated power system

\section{Compensation Principle}

During heavy load Reactive power and transmission losses increases considerably, and lead to the system voltage drop. On the other hand, no or inadequate reactive power adjustment during light load lead to power system voltage rise The main component of power system are reactive, there should be a difference between two terminal voltage values for transmitting the reactive power, but there is limited scope for deviation of terminal voltage from standard ratings so reactive power can only be transmitted in a narrow range of terminal voltages. Since reactive power cannot be transmitted over a long distance, reactive power compensation becomes a required part in power system. Hence reactive power compensation devices should have a strong adjustability and they can operate not only at the inductive area but also capacitive area. SVC and STATCOM are all the devices and gradually obtained extensive application.

\section{Transmission Line Modeling With SVC}

The most common type of the static var compensator is a device comprising of a TCR in parallel with a fixed capacitor as shown in the Fig. 1. It is used for dynamic shunt compensation SVC is composed of a controllable shunt reactor and shunt capacitor, by triggering the thyristors with a certain preset value of the capacitor and reactor ,the equivalent impedance of the circuit can be altered [7] [8]. Total susceptance of the SVC can be controlled by firing thyristors in an appropriate range of firing angles which is typically 90 to 180 degrees. The SVC controls the terminal bus voltage which is the power system control variable controlled. The terminal or V-I characteristic of SVC is illustrated in Fig. 2. 
The equation of the basic circuit are used here are

$$
\begin{gathered}
\mathrm{V}_{\mathrm{j}}=0 \\
\mathrm{P}_{\mathrm{i}}=0 \\
\mathrm{Q}_{\mathrm{i}}=\mathrm{V}_{\mathrm{i}}{ }^{2} \mathrm{~B}
\end{gathered}
$$

Thus we get a function for the reactive power that includes the delay angle

$\mathrm{Q}_{\mathrm{i}}=\mathrm{V}_{\mathrm{i}}^{2}\left(B_{L} \frac{\pi-2 \alpha-\sin 2 \alpha}{\pi}+B_{c}\right)$

Considering this equation in matters of resonance where $\mathrm{B}=0$

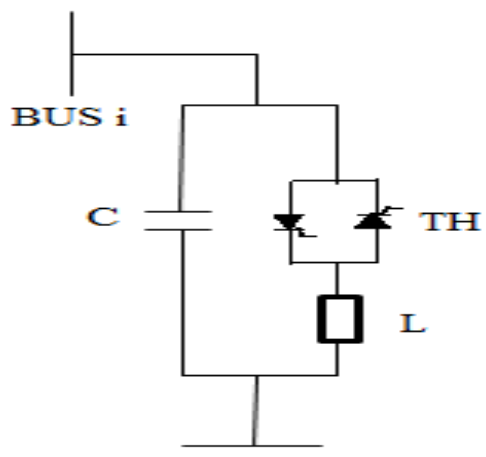

Fig. 1. SVC circuit

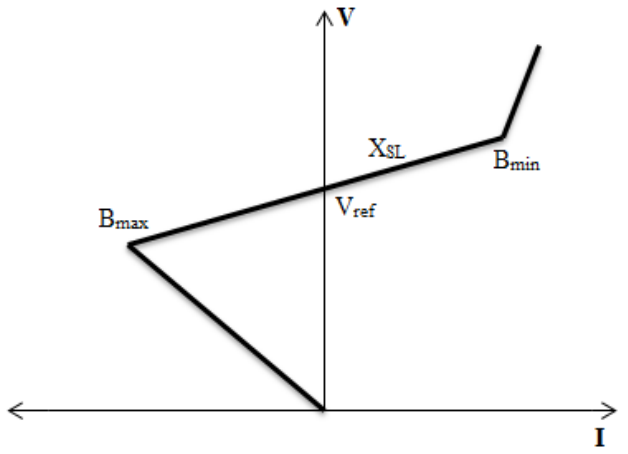

Fig. 2. Voltage-Current characteristic of SVC.

\section{B. Transmission Line Modeling With STATCOM}

If a synchronous machine is running without a prime mover or a mechanical load then by simply controlling the field excitation it can be made to either generate or absorb reactive power. With a proper voltage regulator the reactive power output can be adjusted to maintain constant terminal voltage. It draws a small amount of active power to meet the losses. This working mode is STATCOM .A small drop in a system voltage leads to an instantaneous increase in the reactive power output. The V-I characteristic is shown in Fig. 3

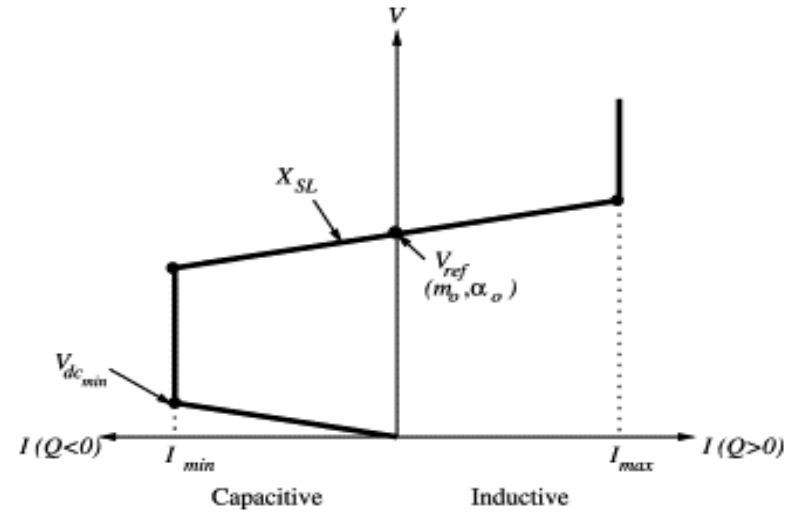

Fig. 3. Voltage-Current characteristic of STATCOM

STATCOM is capable of maintaining rated current at full boost as compared to the characteristic of SVC at full load as shown in Fig 2 and 3.

\section{Transmission Line Modeling With TCSC}

The convenient conditions to control the steady state impedance of a high voltage transmission line is provided by adding both a Thyristor Controlled Series Capacitor (TCSC) and a Thyristor Controlled Series Reactor (TCSR) [5] [6] because series impedance of a high voltage transmission line is usually inductive, with only 5 to 10 percent of resistance. TCSC injected in transmission line is as shown in Fig 4 in form of a general equivalent circuit . The variation of line's impedance can be achieved in two ways. One way is by switching on or off (by passing) the parts of the serially connected capacitor banks (Thyristor Switched Series Capacitor) and the other is by varying the Thyristor Controlled Reactor (TCR) reactance, which is connected parallel to the capacitor (Thyristor Controlled series capacitor). Thus, TCSC can be controlled either in capacitive or in inductive operation range depending on the different applications [2] [6]

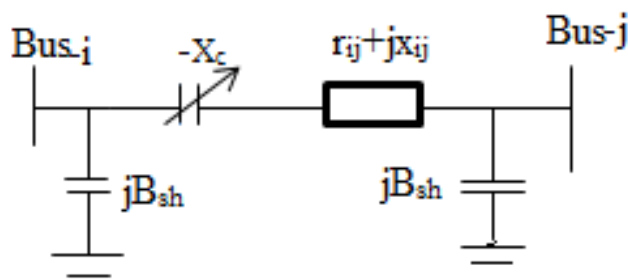

Fig 4 Equivalent circuit of TCSC

\section{PLACEMENT STRATEGY USING LOSS SENSITIVITY INDEX METHOD}

The objective of the device placement may be maximum power transfer in the system, reduction in the total system real power loss, and reduction in the real power loss of a particular line [9]. Out of this the second objective which is the reduction in the total system real power losses has been considered for 
the location of the FACT devices as this offers best result in terms of reduction in losses as well as in maximization of the power transfer in the system.

Loss sensitivity index is a method based on the sensitivity of total active and reactive power loss of the system with respect to control variable of the FACT devices. Considering the control parameters i.e. line reactance (xij) for TCSC placed between buses $i$ and $j$ and reactive power (Qij) for SVC placed between the bus $\mathrm{i}$ and $\mathrm{j}$. The power loss sensitivity index with respect to this control variable can be formulated for both devices as follows

$\mathrm{a}_{\mathrm{ij}}=\frac{\partial Q_{L}}{\partial X_{i j}}$ Loss sensitivity with respect to TCSC

$\mathrm{b}_{\mathrm{ij}}=\frac{\partial P_{L}}{\partial Q_{i}}$ Loss sensitivity with respect to SVC

These factors can be determined at a base load flow solution as given below. Consider a line connected between bus $i$ and $j$ and having a net series impedance of $X_{i j}$ and $Q_{i}$ is the net reactive power injected in the bus $i$. The bus sensitivity index with respect to $X_{\mathrm{ij}}$ is computed as

$$
\frac{\partial Q_{L}}{\partial X_{i j}}=\left[\mathrm{v}_{\mathrm{i}}{ }^{2}+\mathrm{v}_{\mathrm{j}}{ }^{2}-2 \mathrm{v}_{\mathrm{i}} \mathrm{v}_{\mathrm{j}} \cos \left(\delta_{\mathrm{i}}-\delta_{\mathrm{j}}\right)\right] \frac{R_{\mathrm{ij}}{ }^{2}-\mathrm{X}_{\mathrm{ij}}{ }^{2}}{\left(R_{\mathrm{ij}}{ }^{2}+X_{\mathrm{ij}}{ }^{2}\right)^{2}}
$$

Where

$$
\left.\mathrm{Q}_{\mathrm{L}}=\sum_{\mathrm{i}=1 \mathrm{j}=1}^{\mathrm{n}} \sum_{\mathrm{ij}}^{\mathrm{n}}\left(\mathrm{P}_{\mathrm{i}} \mathrm{P}_{\mathrm{j}}+\mathrm{Q}_{\mathrm{i}} \mathrm{Q}_{\mathrm{j}}\right)+\varepsilon_{\mathrm{ij}}\left(\mathrm{Q}_{\mathrm{j}} \mathrm{P}_{\mathrm{i}}-\mathrm{P}_{\mathrm{j}} \mathrm{Q}_{\mathrm{i}}\right)\right]
$$

The loss sensitivity index with respect to SVC is computed as

$$
\mathrm{P}_{\mathrm{L}}=\sum_{\mathrm{i}=1 \mathrm{j}=1}^{\mathrm{n}} \sum_{\mathrm{ij}}\left[\alpha_{\mathrm{ij}}\left(\mathrm{P}_{\mathrm{i}} \mathrm{P}_{\mathrm{j}}+\mathrm{Q}_{\mathrm{i}} \mathrm{Q}_{\mathrm{j}}\right)+\beta_{\mathrm{ij}}\left(\mathrm{Q}_{\mathrm{i}} \mathrm{P}_{\mathrm{j}}-\mathrm{P}_{\mathrm{i}} \mathrm{Q}_{\mathrm{j}}\right)\right]
$$

Where $\alpha, \beta, \gamma$ and $\varepsilon$ are loss coefficients computed from the elements of the bus impedance matrix and the bus voltage defined as:

$$
\begin{aligned}
& \alpha_{i j}=\frac{r_{\mathrm{ij}}}{v_{\mathrm{i}} v_{j}} \cos \left(\delta_{i}-\delta_{j}\right) \\
& \beta_{i j}=\frac{r_{\mathrm{ij}}}{v_{\mathrm{i}} v_{j}} \sin \left(\delta_{i}-\delta_{j}\right) \\
& \gamma_{i j}=\frac{x_{\mathrm{ij}}}{v_{\mathrm{i}} v_{j}} \cos \left(\delta_{i}-\delta_{j}\right) \\
& \varepsilon_{i j}=\frac{x_{\mathrm{ij}}}{v_{\mathrm{i}} v_{j}} \cos \left(\delta_{i}-\delta_{j}\right) \\
& \mathrm{P}_{\mathrm{i}}+\mathrm{j} \mathrm{Q}_{\mathrm{i}} \text { is complex injected power at bus i. }
\end{aligned}
$$

At bus i sensitivity index with respect to SVC parameter using above loss formula can be expressed as:

$$
\frac{\partial P_{L}}{\partial Q_{i}}=2 \sum(\alpha \mathrm{ij} \mathrm{Qi}+\beta \mathrm{ij} \mathrm{Pi}) \quad \mathrm{i}=1 \text { to } \mathrm{n}
$$

\section{CRITERIA FOR OPTIMAL PLACEMENT}

The FACTS devices should be placed on the bus or line with highest sensitivity. When TCSC is to be placed the location is the line with most positive sensitivity index. and when SVC is to be placed, the location is particular bus of the system with most negative sensitivity index. After determining loss sensitivity indices for each type of the FACTS devices, following criteria shall be used for optimal placement [10].

- The TCSC should be placed on a line (m) having most positive loss sensitivity index $a_{k}$

- The SVC should be placed at a bus i having most negative sensitivity index $b_{k}$

Present work includes the two different cases namely reduction of active power losses and reactive power losses. In each case, one of the two FACTS controllers TCSC and SVC is included in the problem formulation

Test results are obtained by considering practical IEEE 5-bus system [11] [12]. OPF solution is obtained on these systems to determine the optimum generation schedule that satisfied the objective of minimizing the losses from the desire transactions and controlling of voltage magnitude. Here the sensitivity index for both TCSC and SVC devices has been calculated for the placement of FACTS devices. The FACTS devices placement method known as sensitivity index has been tested on a 5-bus and IEEE 14 bus system. Single line diagram of 5-bus system as shown in Fig 5 .

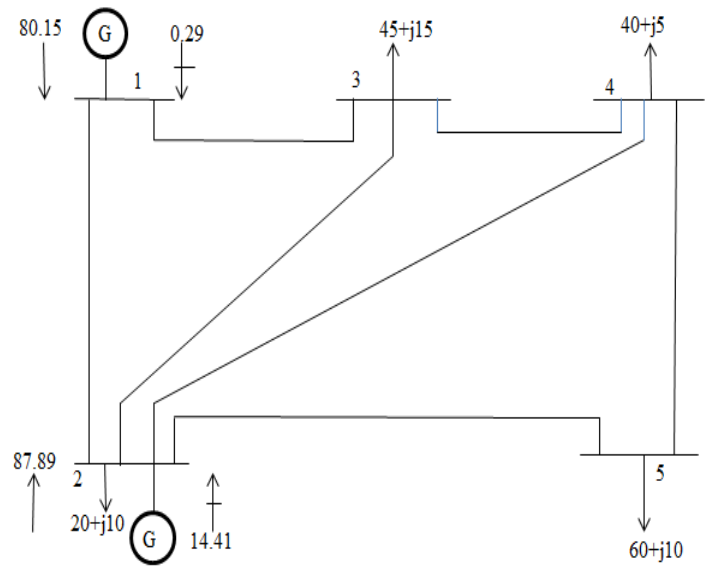

Fig. 5. Five bus systems 
Based upon these method sensitivities are determined for each control parameter of TCSC and SVC placed in every line one at a time for similar operating condition. The sensitivity of 5-buses with respect to TCSC and SVC control parameter are tabulated below. The highest positive sensitivities $a_{k}$ and the highest negative sensitivity index $b_{k}$ are presented in bold for placement of FACTS devices, from comprising of results on different busses and lines the best location for placement of TCSC and SVC can be decided.

Case 1: Five- Bus System

The five bus system with two generators and four load buses are as shown in Fig 5.

Values of sensitivity index $a_{k}$ and $b_{k}$ for this test system are given in table 1 and 2 . After calculating the sensitivity index for 5-bus system on TCSC and SVC the optimal location can be obtained. The most sensitive index is shown as bold in the following tables.

Table I

5-Bus System Loss Sensitivity Index $a_{k}$

\begin{tabular}{|c|cc|c|}
\hline \multicolumn{3}{|c|}{5 - Bus System } & $\begin{array}{l}\text { Sensitivity } \\
\text { index }\end{array}$ \\
\hline Line & From To & $\mathrm{a}_{\mathrm{k}}$ \\
\hline 1 & 1 & 2 & -0.1665 \\
\hline 2 & 1 & 3 & -0.0726 \\
\hline 3 & 2 & 3 & -0.0529 \\
\hline 4 & 2 & 4 & -0.0635 \\
\hline 5 & 2 & 5 & -0.2135 \\
\hline \hline 6 & 3 & 4 & $\mathbf{0 . 0 0 0 0}$ \\
\hline \hline 7 & 4 & 5 & -0.0003 \\
\hline
\end{tabular}

Table II

5-Bus System Loss Sensitivity Index $b_{k}$

\begin{tabular}{|c|c|}
\hline 5-Bus System & Sensitivity Index $b_{\mathrm{k}}$ \\
\cline { 1 - 2 } Bus No & 0.3282 \\
\hline \hline 1 & $\mathbf{- 0 . 0 3 0 6}$ \\
\hline \hline 2 & 0.1218 \\
\hline \hline 4 & 0.2097 \\
\hline 5 & 0.1923 \\
\hline
\end{tabular}

It is evident from above tables that $a_{k}$ is most positive sensitivity index between line number 3-4, and $b_{k}$ has most negative sensitivity index at bus number 2 but as the bus number 2 is generator bus therefore SVC must be placed at bus number 3 which has negative sensitivity index with respect to another load buses. These values signify the location of both TCSC and SVC devices in 5- bus system these location offer best results in terms of increase in active power generation with minimization of real and reactive power losses.

After selecting the location for placing the TCSC and SVC device in transmission line 3-4 and bus number 3 respectively the real and reactive powers as determined as indicated in Table III

Table III

Comparison of Result on Different Busses and Lines for 5-Bus Systems

\begin{tabular}{|c|c|}
\hline Base case & $\mathrm{P}_{\text {loss }}+\mathrm{j} \mathrm{Q}_{\text {loss }}$ \\
\cline { 2 - 2 } & $3.051+9.15 \mathrm{j}$ \\
\hline TCSC installed between 3-4(6) & $3.051+9.12 \mathrm{j}$ \\
\hline TCSC installed between 4-5(7) & $3.052+9.13 \mathrm{j}$ \\
\hline SVC installed on bus no. 3 & $3.015+9.04 \mathrm{j}$ \\
\hline SVC installed on bus no. 4 & $3.024+9.07 \mathrm{j}$ \\
\hline
\end{tabular}

From table III it is clear that optimal placement of TCSC in line 3-4 is more effective than placing the TCSC on line 4-5. System power losses after placing TCSC in line 6-7 are shown table III placement of TCSC on line no 7 may increase the power flow but overall losses are increased as compared to TCSC placed on line 6. Similarly the placement of SVC on bus no 3 is more effective than the placement of SVC on bus no 4 where the objective is to maintain the voltage magnitude $1 \mathrm{p} . \mathrm{u}$ placement of SVC on bus no 3 results in less power losses as compared to bus no 4.

After deciding the optimal location and comparing the results on different lines and busses we can simulate the optimal power flow on a given test network and results can be compared with and without FACTS devices with the objective of minimization of active and reactive power losses on different bus systems.

\section{TEST SYSTEM RESULTS WITH FACTS DEVICES}

This section presents power flow after placement of the device, voltage magnitude real and reactive powers results for base case and TCSC and SVC devices placed in the line after finding the sensitivity index for each bus and lines with certain conditions are shown in table for 5-bus system.

\section{A. Results on 5-bus system with SVC}

Different values of cost, real and reactive power losses with corresponding values of voltage magnitude are determined and compared with base case( no device is placed ). Shown in table IV. Here five bus test network is tested with considering the effect of single SVC and TCSC placed on 5-bus system networks.

The five-bus system shown in Fig 5 is modified to include on e SVC at bus number 3 as shown in the Fig 6. The objective is to minimize its active power generation cost. 


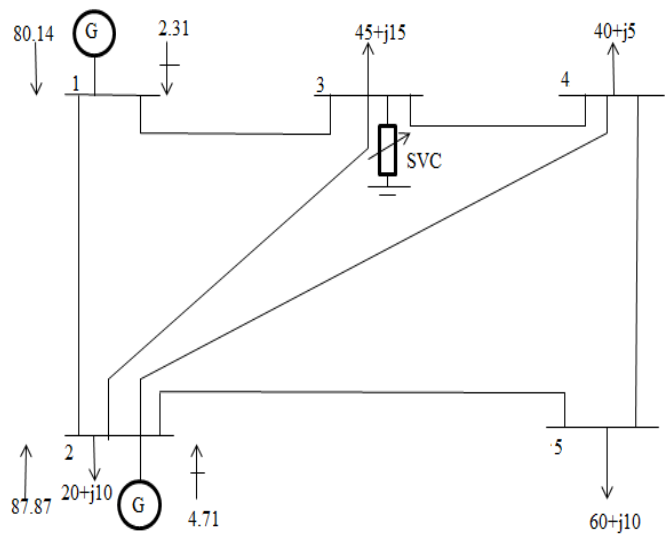

Fig. 6 SVC- Upgraded Five-Bus System and Optimal Power Flow Solution

The results obtained on five bus systems indicate that in order to maintain the voltage magnitude at main at 1.1 p.u. It is necessary for the SVC to inject more reactive power. it should be noted that the minus sign indicates injection of reactive power. The power flow results are shown in table I by installing the FACTS devices on bus no 3 . The optimal power flow results are $29913.12 \mathrm{Rs} / \mathrm{h}$, 3.015MW and 9.04 MVAR. This results in decrease in the cost and losses on the whole system network.

\section{Results on 5-bus system with TCSC}

The five-bus system in the Fig 5 is modified to include one TCSC between bus number 3 and bus number 4 as shown in Fig VI. The objective is to minimize respective power losses and generation cost. TCSC is modelled as an adjustable, nonlinear series reactance which is a function of TCSC. Because one of the applications of TCSC is reactive line compensation, the TCSC is tested in this field of operation.

The OPF solution is a achieved in seven iteration and the device TCSC optimizes the active power flow level in transmission line 3 and 4 . Moreover, the optimal power flow solution yields the following minimum active generation cost and network losses 29919.20Rs/h and 3.053 MW respectively. The TCSC capacitive and inductive reactance value required to achieve the results are: $\mathrm{X}_{\mathrm{c}}=0.9375 \%$ and $\mathrm{X}_{\mathrm{L}}=0.1625 \%$ respectively, using a base voltage of $400 \mathrm{kV}$. The OPF are shown in the Fig 7.

\begin{tabular}{|c|c|c|c|}
\hline Quantity & $\begin{array}{c}\text { Values without } \\
\text { FACTS devices }\end{array}$ & $\begin{array}{c}\text { Values } \\
\text { with SVC }\end{array}$ & $\begin{array}{c}\text { Values with } \\
\text { TCSC }\end{array}$ \\
\hline $\begin{array}{c}\text { Active power generation cost } \\
(\mathrm{RS} / \mathrm{H})\end{array}$ & 29919.20 & 29913.12 & 29919.09 \\
\hline Active power loss & 3.051 & 3.015 & 3.015 \\
\hline Active power generation (MW) & 168.05 & 168.01 & 168.05 \\
\hline Reactive power loss (MVAR) & 9.15 & 9.04 & 9.12 \\
\hline
\end{tabular}

Table IV: OPF Solution on 5 Bus System

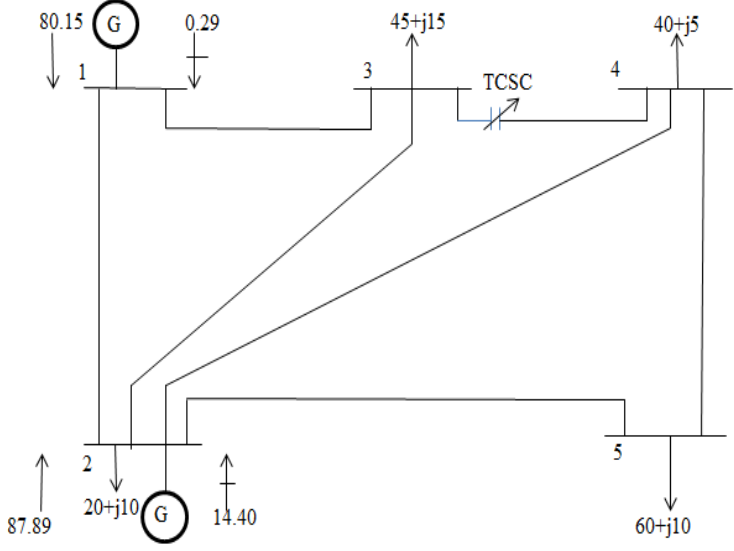

Fig. 7 TCSC- Upgraded Five-Bus System and Optimal Power Flow Solution

It can be observed that optimal power flow solution changes little compared with the base OPF case presented in section IV When no TCSC is used. This may be explained by the fact that the solution achieved in section IV is already a good solution and that the OPF is fixing the level of compensation afforded by the TCSC to be fairly a small.

In table IV column 2,3 and 4 of row 1 , compares the results obtained for the optimal cost of active power generation with and without FACTS devices. While row 3,4 and 5 provide the loss of real and reactive power in p.u. with and without FACTS(TCSC and SVC) installed in location mentioned in the first column of the table III the results are compared with the base case without FACTS devices.

It can be observed that OPF solution changes little compared with base OPF case presented in the table III when no TCSC is used. This may be explained by the fact that the solution achieved in the table IV is already a very good solution and that the OPF is fixing the level of compensation afforded by TCSC to be very small. 


\section{CONCLUSION}

A new method to seek the optimal location and capability of shunt FACTS devices based on sensitivity analysis is presented in this paper. Firstly order the weak bus according to sensitivity and then select the optimal scheme of location. After selecting the optimal location we find active and reactive power losses and cost with and without FACTS devices. Simulation of IEEE 5-bus system for different scenarios shows that the placement of different FACTS devices improve the power transfer capability and reduce the cost.

\section{REFERENCES}

[1]. G.H. Hingorani," Flexible AC transmission system", IEEE spectrum, Apr 1993.

[2]. D.J. Gotham and G.T. Heydt,"Power flow control and power flow studies for system with FACTS devices," IEEE Trans, power system, Vol. 13, no.1, Feb 1998.

[3]. Preecha Preedavichit and S.C.Srivastava," Optimal reactive power dispatch considering FACTS devices," Electrical power research, vol. 48, pp. 251-257, May 1995.

[4]. H.C. Leung and T.S. Chung," Optimal power flow with a versatile FACTS controller by Genetic Algorithm approach," Proceeding of the $5^{\text {th }}$ international conference on "Advances in power system control, operation and management", APSCOM 2000 Oct, pp. 178-183.

[5]. W.O. Stadlin and D.L. Fletcher," voltage versus Reactive current model for Dispatch and control," IEEE Transactions on Power Apparatus and Systems, vol.PAS-101, no. 10, pp. 3751-3758, Oct 1982.

[6]. M.Nomizain and G.Andersson," Power flow control by use of controllable series components," IEEE Transactions on Power Delivery, vol. 8, no. 3, pp. 1420-1429, July 1993.

[7]. H.Ambriz.Perez, E. Acha, and C.FuerteEsquivel," Advanced SVC models for Newton-Raphson load flow and Newton optimal power flow studies," IEEE Power Transactions on Power Systems, vol. 15, pp. 129-136, Feb 2000.

[8]. Huang Garng, M.Yan, Ping," TCSC and SVC as re-dispatch tools for congestion management and TTC improvement," IEEE Power Transactions on Power Systems, pp. 660-665, May 2002.

[9]. N.G. Hingorani and L. Gyugyi, Understanding FACTS: Concepts and technology of Flexible AC Transmission Systems, IEEE Press, ISBN 0-7803-3455-8, 2000.
[10]. S.Srivastava and P. Kumar," Optimal power dispatch in deregulated market considering congestion management," in Proc. Int. Conf. Electric Utility Deregulation and Restructuring and Power Technologies, London, U.K, pp. 4-7, Apr 2000.

[11]. IEEE 5-bus test system data [Online]. Available:

http://www.ee.washington.edu/research/pstc a/pf/pg_tcal5bus.htm.

[12]. IEEE 14-bus test system data [Online]. Available:

http://www.ee.washington.edu/research/pstc a/pf/pg_tcal5bus.htm. 